\title{
Basal forebrain and memory: Neurotoxic lesions impair serial reversals of a spatial discrimination
}

\author{
ANNE PETERNEL, DONNA HUGHEY, GARY WENK, and DAVID OLTON \\ The Johns Hopkins University, Baltimore, Maryland
}

\begin{abstract}
The role of the basal forebrain (BF) in spatial memory was evaluated by testing rats with $\mathrm{BF}$ lesions in the acquisition and reversal of a two-choice spatial discrimination. BF lesions were made by injecting ibotenic acid into the medial septal area and nucleus basalis magnocellularis. Behavioral testing was conducted in a T-maze. Rats were given a spatial discrimination in which food was located in only one of the arms. After successful performance in this discrimination, each rat was given a series of discrimination reversals. Control rats learned rapidly and performed well. BF rats had a significant impairment in all reversals, even the last one, which was given approximately 6 weeks postoperatively. These data show that the BF is necessary for normal spatial memory and reversal learning, and they are discussed in the context of the role of the $\mathrm{BF}$ in different types of memory processes.
\end{abstract}

The basal forebrain (BF) cholinergic system contains magnocellular cholinergic neurons that have projections to the frontal cortex and the hippocampus (Bigl, Woolf, $\&$ Butcher, 1982). BF lesions in rats and monkeys have impaired performance in many tasks assessing recent memory (see reviews in Olton \& Wenk, 1987; Wenk \& Olton, 1987); these changes are similar to those seen after lesions of the medial septal area and hippocampus (Gray \& McNaughton, 1983; O'Keefe \& Nadel, 1978) and after injections of anticholinergic drugs such as atropine and scopolamine (Bartus, Dean, Pontecorvo, \& Flicker, 1985; Spencer, Pontecorvo, \& Heise, 1985). In some tasks, an initial impairment was followed by a recovery of function that was often sufficient to return choice accuracy to normal (Bartus, Flicker, et al., 1985; Hepler, Olton, Wenk, \& Coyle, 1985; Knowlton, Wenk, Olton, \& Coyle, 1985; Ridley, Baker, Drewett, \& Johnson, 1985). In other tasks, the impairment persisted throughout testing (Murray \& Fibiger, 1985).

The present experiment was designed to expand our knowledge of the behavioral effects of BF lesions in two ways. First, we used a new task, successive reversals of a spatial discrimination. Second, we continued testing for 5 weeks to determine the extent of recovery of function.

\section{METHOD}

\section{Subjects}

Eighteen male Long-Evans rats were housed in standard wiremesh cages with free access to water in a colony room with a 16:8h light:dark cycle with lights on at 7:00 a.m. All behavioral test-

This research was supported in part by Research Grant AG05146 from the National Institute of Aging. The authors thank D. Harris for preparing the manuscript and the reviewers for some insightful comments regarding revisions of the original manuscript. Address correspondence to David Olton, Department of Psychology, The Johns Hopkins University, Baltimore, MD 21218. ing took place during the light part of the cycle. Following surgery, each rat was food deprived to $85 \%$ of its ad-lib weight, allowing a 5-g increase per week for normal growth. After training procedures were initiated, an appropriate amount of Charles River rat formula was fed to every rat after daily testing. The BF group consisted of 9 rats with bilateral BF lesions. The control group consisted of 9 rats that had had control operations that did not produce lesions.

\section{Apparatus}

The T-maze used in this experiment was identical to the one described by Hepler, Olton, et al. (1985). On all sides of the starting platform, stem, and arms was a wooden edge, $2 \mathrm{~cm}$ high. The starting platform was separated from the stem by a guillotine door, $12 \mathrm{~cm}$ high and $6 \mathrm{~cm}$ wide, mounted in a frame that was $23 \mathrm{~cm}$ high and $15 \mathrm{~cm}$ wide. The stem was divided into halves by a hardware cloth partition, $12 \mathrm{~cm}$ high and $32 \mathrm{~cm}$ long, which started $24 \mathrm{~cm}$ from the guillotine door. At the end of the partition next to the arms, on each side of the stem, was a white opaque curtain, $14 \mathrm{~cm}$ high and $7 \mathrm{~cm}$ wide. These curtains were suspended from a frame, $14 \mathrm{~cm}$ high and $15 \mathrm{~cm}$ wide, that was perpendicular to the stem. A clear Plexiglas barrier, $14 \mathrm{~cm}$ high and $8 \mathrm{~cm}$ wide, was placed behind the left curtain to block access to the arms from that side of the stem. A food cup, $1 \mathrm{~cm}$ wide and $2 \mathrm{~cm}$ deep, was located $1 \mathrm{~cm}$ from the distal end of each arm.

\section{Procedure}

\section{Surgery}

Thirty minutes after i.p. injection or $.25 \mathrm{cc}$ of $.5 \mathrm{mg} / \mathrm{ml}$ atropine methyl bromide, each rat was anesthetized with sodium pentobarbital ( $50 \mathrm{mg} / \mathrm{kg}$; Fort Dodge Laboratory, Fort Dodge, LA). The rat was then placed in a stereotaxic instrument so that bregma and lambda were in the same horizontal plane. Coordinates for the injection site for the medial septal area (MSA) lesions were $0.8 \mathrm{~mm}$ anterior to bregma, on the midline, and $5.8 \mathrm{~mm}$ ventral from dura; $6 \mu \mathrm{g}$ of ibotenic acid in $600 \mathrm{nl}$ of phosphate-buffered saline was injected over a period of $5 \mathrm{~min}$. Coordinates for the injection site for the nucleus basalis magnocellularis (NBM) lesions were $0.8 \mathrm{~mm}$ and $0.4 \mathrm{~mm}$ posterior to bregma, $\pm 2.6 \mathrm{~mm}$ lateral to the central sinus, and $6.9 \mathrm{~mm}$ ventral from top of skull; $4 \mu \mathrm{g}$ of ibotenic acid in $400 \mathrm{nl}$ of phosphate-buffered saline was injected over a period of $5 \mathrm{~min}$. The rats that received control operations were treated identically except that the cannula was lowered to a point $1 \mathrm{~mm}$ above 
the site used for rats that received lesions, and nothing was injected into the brain.

\section{Behavior}

Shaping. The rats were handled for 5 min daily for 2 weeks prior to surgery. One week after surgery, each rat was shaped for 6 days to go to the ends of the maze arms for a reward of Thrive cat food (Purina). During the first day of training, food was scattered all over the maze. Subsequently, the food was placed progressively closer to the ends of the arms until it was put only in the food cup at the end of each arm.

Discrimination. Two discriminations were presented to the rat. The first was a left-right discrimination in the stem of the maze. For the entire testing period, the right side of the stem allowed access to the arms, and the left side of the stem was blocked; consequently, the correct response in the stem was always to go to the right side. The second discrimination was a left-right discrimination in the arms of the maze. One arm contained food; the other did not. Consequently, the correct response in the arm discrimination was to go to the arm with food. The arm discrimination, but not the stem discrimination, was reversed after the rat reached criterion performance on each discrimination so that the arm containing food was changed during the testing period.

For each rat, the baited arm had one piece of Thrive in its food cup. The other, unbaited, arm had no food at its end. For each trial, the rat was placed on the starting platform, the guillotine door was raised, and the rat was allowed to go down the stem of the maze. An incorrect stem choice was recorded when the rat entered the left side of the stem and placed all four paws beyond the edge of the hardware cloth partition. The rat was allowed to correct any mistakes made in the stem. A correct stem choice was recorded when the rat went directly from the starting platform to the right side of the stem.

The rat was then allowed to run to the end of one of the maze arms. If the rat reached the end of the baited arm, a correct arm choice was recorded and the rat was allowed to eat the food. If the rat went to the end of the unbaited arm, an incorrect arm choice was recorded. Once an arm choice was made, whether correct or incorrect, the rat was returned to the starting platform with the guillotine door closed. After $5 \mathrm{sec}$, a new trial began with the opening of the guillotine door.

Each test session consisted of 30 trials with an intertrial interval of approximately $5 \mathrm{sec}$. The rats were tested daily for 6 weeks.

Reversal. Each rat was trained in the initial discrimination until it made (1) at least 14 correct arm choices during the last 15 trials of a given day of training, and (2) at least four correct arm choices during the first five trials of the following day of training. The discrimination was then reversed on the next trial so that the previously unbaited arm was baited, and the previously baited arm was unbaited. Each rat was tested to the same criterion and then given another reversal. This procedure continued for 6 weeks.

\section{Biochemistry}

Thirteen of the rats were sacrificed by decapitation; tissue samples were obtained from the hippocampus and from neocortical areas 2 and 10 (Krieg, 1946). The effectiveness of the lesions was determined by a decrease in the levels of choline acetyltransferase (ChAT) activity (Fonnum, 1975). Protein was assayed by the method of Lowry, Rosebrough, Farr, and Randall (1951).

\section{RESULTS}

\section{ChAT Levels}

ChAT levels were measured in a 6 control rats and $7 \mathrm{BF}$ rats. The control rats had a mean ChAT level of $58.4 \pm 15.3$ and $80.21 \pm 17.7 \mathrm{nmol} / \mathrm{mg}$ of protein per hour in the frontolateral cortex and hippocampus, respectively. The BF rats had significantly decreased ChAT activity in both areas. The mean ChAT level in the BF rats was reduced to $68 \%$ of the control value in the frontolateral cortex $[t(11)=2.43, p<.025]$ and to $48 \%$ of the control value in the hippocampus $[t(12)=5.41, p<.001]$. Histological descriptions of the lesions in the BF and neurochemical descriptions of the changes in the projection areas have been provided in detail elsewhere (Hepler, Olton, et al., 1985; Hepler, Wenk, Cribbs, Olton, \& Coyle, 1985; Olton \& Wenk, 1987; Wenk, Cribbs, \& McCall, 1984).

\section{Behavior}

\section{Initial Discrimination}

The control rats learned the initial discrimination rapidly, taking a mean of 119 trials to reach criterion performance. Only 1 control rat consistently failed to complete all 30 trials in a day's session and was dropped from the experiment. The BF rats reached criterion in a mean of 134 trials, which was not significantly greater than the score of the control rats $[t(13)=.229, p>.25]$. Two $\mathrm{BF}$ rats failed to reach criterion after 1,500 trials (50 days) of testing. The data from these rats were not included in any subsequent analysis.

\section{Reversals}

General. Both groups of rats continued to go down the stem and arms of the maze and eat the food when they made a correct response. In the stem discrimination, which was not reversed, the rats almost never made an error. Consequently, data are presented only for the arm discrimination.

Trials to criterion. The control rats took a mean of 79 trials to reach criterion during the first reversal. Performance improved slightly (but not significantly) in the subsequent reversals, and the mean number of trials to criterion ranged from 56 to 64 for Reversals 2-5 and the last reversal (see Figure 1). All of the BF rats also learned each of the reversals, but took more trials to do so. The mean number of trials to criterion was 107 for the first reversal, and ranged from 94 to 176 for Reversals 2-5 and the last reversal. A 2 (groups) $\times 6$ (reversals) analysis of variance (ANOVA) showed a main effect of group, indicating that the $\mathrm{BF}$ rats took significantly more trials to reach criterion than the control rats $[F(1,13)=13.0$, $p<.005]$.

Choice accuracy: Trials 1-5. During the first five trials of the first reversal, the control rats showed a marked decrease in choice accuracy from the previous criterion run in the initial discrimination. In subsequent reversals, the mean number of correct arm responses during the first five trials ranged from 1.1 to 3.3, a slight but statistically insignificant increase (see Figure 2, upper left). Although the BF rats made more correct arm responses than the control rats during the first five trials of the first reversal, during all subsequent reversals they made fewer correct arm responses. A 2 (groups) $\times 6$ (reversals) 


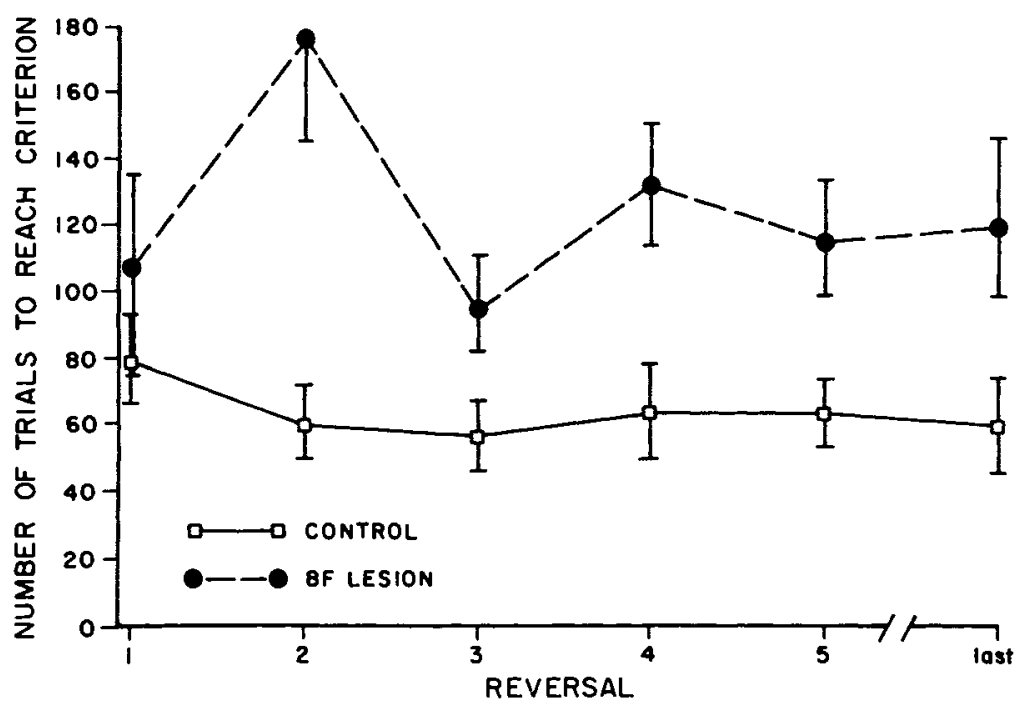

Figure 1. The mean (and standard error of the mean) of the number of trials to reach criterion performance during each of the first five reversals and the last reversal for the control group and the basal forebrain (BF) lesion group.

ANOVA showed a significant main effect of group, indicating that the $\mathrm{BF}$ rats were impaired relative to the control rats $[F(1,13)=16.45, p<.001]$.

Choice accuracy: Trials 6-10. During the second block of five trials, the control rats improved their choice accuracy relative to the first block of five trials (see Figure 2, lower left). Their mean number of correct arm responses during the first reversal was 2.1. Choice accuracy gradually improved during the reversals, and the mean number of correct arm responses ranged from 2.8 to 4.6. The BF rats showed a consistent impairment in all of the reversals and their mean number of correct arm responses ranged from 1.7 to 3.1 during the six reversals. A 2 (groups) $\times 6$ (reversals) ANOVA showed a significant main effect of group $[F(1,13)=9.15, p<.01]$, indicating that the BF group performed worse than the control group, and a significant main effect of reversals $[F(5,9)=7.33, p<.005]$, indicating that the rats improved their choice accuracy as they acquired more experience with the reversal procedure.

Choice accuracy: Trials 11-15. The control rats performed better during the third block of five trials of the reversals than in the first and second blocks of five trials (see Figure 2, upper right). Their mean number of correct arm responses ranged from 3.1 to 5.0. The BF rats were impaired relative to the control rats; their mean number of correct arm choices ranged from 1.9 to 4.0. A 2 (groups) $\times 6$ (reversals) ANOVA revealed a significant main effect of group $[F(1,13)=11.74, p<.005]$.

Choice accuracy: Trials 16-20. The control rats continued to perform better than the BF rats in the fourth block of five trials of each reversal (see Figure 2, lower right). The mean number of correct arm choices for the control rats ranged from 3.9 to 5 , whereas that of the BF rats ranged from 2.6 to 3.8 . A 2 (groups) $\times 6$ (reversals) ANOVA demonstrated a significant main effect of group during this block of trials $[F(1,13)=19.44, p<.001]$.

Number of reversals. Each rat was given 35 days of testing. The control rats completed a mean of 13 reversals (range: 9-20); the BF rats completed a mean of 9.6 (range: 5-19).

\section{DISCUSSION}

Loss of BF neurons produced a significant and enduring deficit in the ability of rats to learn a reversal of a two-choice simultaneous spatial discrimination in a Tmaze. This impairment remained throughout testing, and its magnitude was not substantially reduced even during the last reversal, which took place approximately 6 weeks after surgery. Choice accuracy of both control and BF rats improved as a result of experience with the reversal procedure, but the relative difference between the two groups remained constant. Consequently, these data indicate that integrity of the BF is necessary for normal performance of this task.

Lesions of the NBM or MSA have impaired performance in a variety of spatial discriminations, including delayed nonmatching-to-sample in a T-maze (Murray \& Fibiger, 1985; Hepler, Olton, et al., 1985), performance in a radial arm maze (Bartus, Flicker, et al., 1985), and food searching in an open field (Murray \& Fibiger, 1986). Combined lesions of the MSA and NBM impaired performance in the reversal of a spatial discrimination in a T-maze (Hepler, Olton, et al., 1985), but that experiment assessed only one discrimination reversal. The present experiment confirmed these results with a slightly different testing procedure, and the results indicate that the be- 


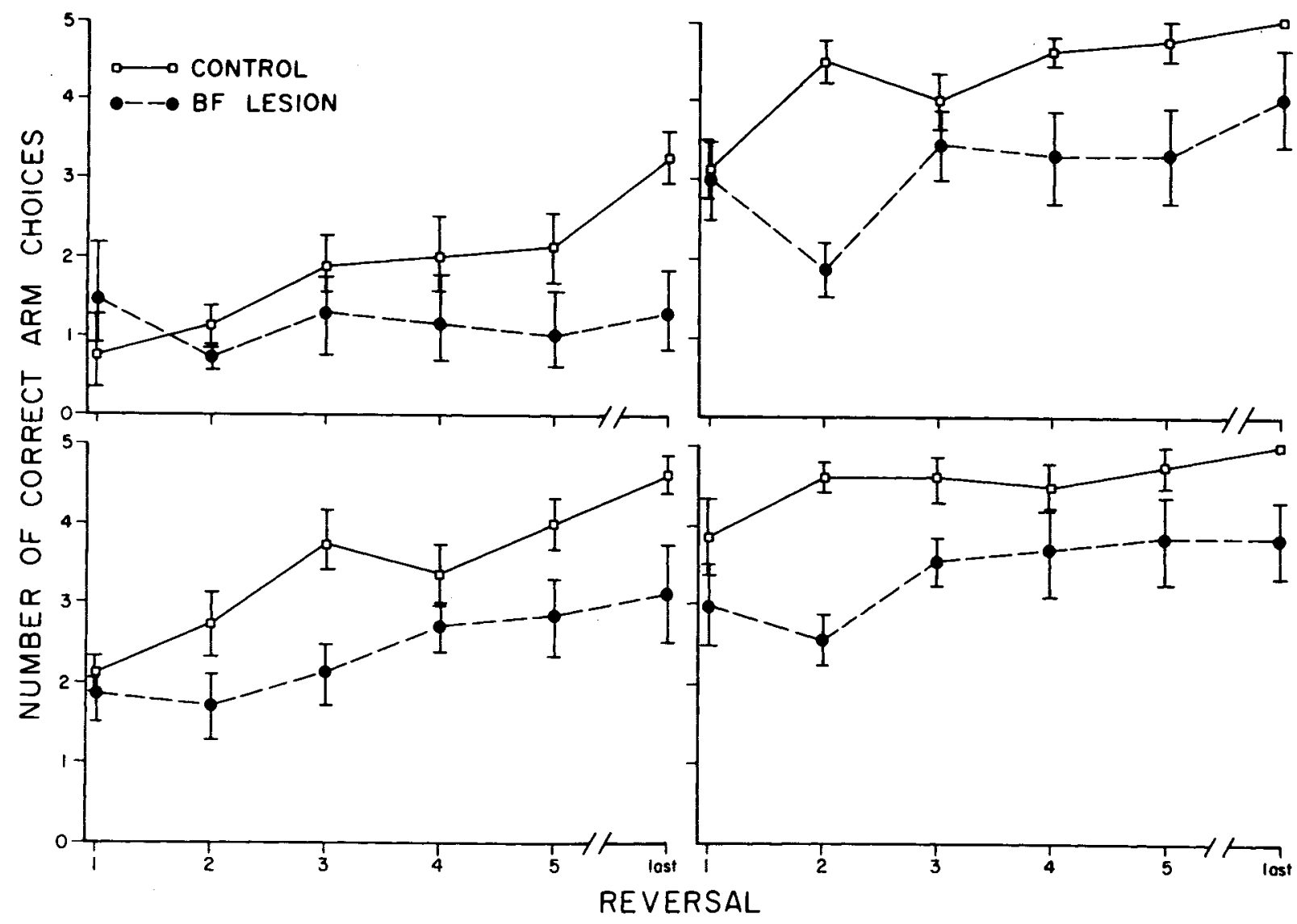

Figure 2. The mean (and standard error of the mean) of the number of correct responses during each of the first five reversals and the last reversal for the control group and the basal forebrain (BF) lesion group: upper left, first block of five trials; lower left, second block of five trials; upper right, third block of five trials; lower right, fourth block of five trials.

havioral impairments persist through at least five additional reversals. This contained impairment in the reversal process is striking, in view of the recovery of performance seen in some other tasks (Bartus, Flicker, et al., 1985; Hepler, Olton, et al., 1985), and suggests that this procedure may be a more sensitive assessment of BF function than were those tasks in which recovery was observed (see also Murray \& Fibiger, 1985, 1986).

The analysis of choice accuracy in successive blocks of five trials in each reversal suggests that the rats with BF lesions had difficulty with all components of the reversal process. Although they obviously did reach criterion performance in each reversal, the rate of acquisition was slower during each of the first four blocks of five trials. The persistence of the impairment suggests that procedures using the repeated reversal of a discrimination, especially one that is trained to a strong criterion of performance, may be very sensitive measures of BF dysfunction.

The behavioral effects of lesions in the frontal cortex, MSA (Gray \& McNaughton, 1983; Kolb, 1984), hippocampus (Gray \& McNaughton, 1983; O'Keefe and Nadel, 1978), and the MSA and NBM components of the basal forebrain (Olton \& Wenk, 1987; Wenk \& Olton, 1987 ) indicate a large number of similarities. In certain behavioral tests, behavioral dissociations did occur (Meck, Church, Wenk, \& Olton, 1987; Olton, Wenk, Church \& Meck, in press), but in most tasks, the pattern of behavioral changes has been similar following these different lesions, suggesting that all of these structures participate in mnemonic processing.

Assessing the functional importance of the BF has become important for two reasons. First, this area of the brain shows degeneration during Alzheimer's disease (Bigl et al., 1982). Second, both the cholinergic system and its projection areas in the frontal cortex and the hippocampus have been closely linked to spatial and mnemonic functions (see reviews in Bartus, Dean, Beer, \& Lippa, 1982; Olton \& Wenk, 1987; Wenk \& Olton, 1987). The results reported here, and those from previous studies, suggest that these projections from the BF are necessary for flexible responding in spatial discriminations.

\section{REFERENCES}

Bartus, R. T., Dean, R. L., Beer, B., \& Lippa, A. S. (1982). The cholinergic hypothesis of geriatric memory dysfunction. Science, 217, 408-417.

Bartus, R. T., Dean, R. L., Pontecorvo, M. J., \& Flicker, C. 
(1985). The cholinergic hypothesis: A historical overview, current perspective, and future directions. In D. S. Olton, E. Gamzu, \& S. Corkin (Eds.), Memory dysfunction: An integration of animal and human research from preclinical and clinical perspectives (pp. 332358). New York: The New York Academy of Sciences.

Bartus, R. T., Flicker, C., Dean, R. L., Pontecorvo, M. J., Figueiredo, J. C., \& Fisher, S. K. (1985). Selective memory loss following nucleus basalis lesions: Long-term behavioral recovery despite persistent cholinergic deficiencies. Pharmacology, Biochemistry \& Behavior, 23, 125-135.

Bigl, V., Woolf, N. J., \& Butcher, L. L. (1982). Cholinergic projections from the basal forebrain to frontal, parietal, temporal, occipital, and cingulate cortices: A combined fluorescent tracer and acetylcholinesterase analysis. Brain Research Bulletin, 8, 727-749.

FonNum, F. (1975). A rapid radiochemical method for the determination of choline acetyltransferase. Journal of Neurochemistry, 24, 407-409.

Gray, J. A., \& McNaughton, B. N. (1983). A comparison between the behavioural effects of septal and hippocampal lesions: A review. Neuroscience \& Biobehavioral Reviews, 7, 119-188.

Hepler, D. J., Olton, D. S., Wenk, G. L., \& Coyle, J. C. (1985). Lesions in nucleus basalis magnocellularis and medial septal area produce qualitatively similar memory impairments. Journal of Neuroscience, 5, 866-873.

Hepler, D. J., Wenk, G. L., Cribbs, B. L., Olton, D. S., \& Coyle, J. T. (1985). Memory impairments following basal forebrain lesions. Brain Reseach, 346, 8-14.

Knowlton, B. J., Wenk, G. L., Olton, D. S., \& Coyle, J. T. (1985). Basal forebrain lesions produce a dissociation of trial-dependent and trial-independent memory performance. Brain Research, 345, 315-321.

KolB, B. (1984). Functions of the frontal cortex of the rat: A comparative review. Brain Research Reviews, 8, 65-98.

KRIEG, W. J. S. (1946). Connections of the cerebral cortex: I. The albino rat: A. Topography of the cortical areas. Journal of Comparative Neurology, 84, 221-275.

Lowry, O. H., Rosebrough, N. J., Fark, A. L., \& Randall, R. J. (1951). Protein measurement with Folin phenol reagent. Journal of Biology \& Chemistry, 193, 265-275.
Meck, W. H., Church, R. M., Wenk, G. L., \& Olton, D. S. (1987). Nucleus basalis magnocellularis and medial septal area lesions differentially impair memory. Journal of Neuroscience, 7, 3505-3511.

MURRAY, C. L., FiBIGER, H. C. (1985). Learning and memory deficits after lesions of the nucleus basalis magnocellularis: Reversal by physostigmine. Neuroscience, 14, 1025-1032.

MurRay, C. L., \& Fibjger, H. C. (1986). Pilocarpine and physostigmine attenuate spatial memory impairments produced by lesions of the nucleus basalis magnocellularis. Behavioral Neuroscience, 100, 23-32.

O'KeEFE, J., \& NADEL, L. (1978). The hippocampus as a cognitive map. Oxford: Clarendon Press.

Olton, D. S., WENK, G. L. (1987). Animal models of the cognitive impairments produced by degeneration of the basal forebrain cholinergic system. In H. Y. Meltzer (Ed.), Psychopharmacology: The third generation of progress (pp. 941-953). New York: Raven Press.

Olton, D. S., Wenk, G. L., Church, R. M., \& Meck, W. H. (in press). Attention and the frontal cortex as examined by simultaneous temporal processing and lesions of the basal forebrain cholinergic system. Neuropsychologia.

Ridley, R. M., Baker, H. F., Drewett, B., \& Johnson, J. A. (1985). Effects of ibotenic acid lesions of the basal forebrain on serial reversal learning in marmosets. Psychopharmacology, 86, 438-443.

Spencer, D. G., Pontecorvo, M. J., \& Heise, G. A. (1985). Central cholinergic involvement in working memory: Effects of scopolamine on continuous nonmatching and discrimination performance in the rat. Behavioral Neuroscience, 99, 1049-1065.

Wenk, G. L., Crubbs, B., \& McCall, L. (1984). Nucleus basalis magnocellularis: Optimal coordinates for selective reduction of choline acetyltransferase in frontal neocortex by ibotenic acid injections. $E x$ perimental Brain Research, 56, 335-340.

WENK, G. L., \& OLTON, D. S. (1987). Basal forebrain cholinergic neurons and Alzheimer's disease. In J. Coyle (Ed.), Experimental models of dementing disorders: A synaptic neurochemical perspective (pp. 81101). New York: Alan R. Liss.

(Manuscript received July 28, 1987; revision accepted for publication February 3, 1988.) 